\title{
Modeling of Transient Pneumatic Events in a Combined Sewer Overflow Storage Tunnel System
}

\author{
Peter Klaver, ${ }^{1}$ David Collins, ${ }^{2}$ Kurt Robinson ${ }^{3}$ and Scott Bell ${ }^{1}$ \\ ${ }^{1}$ LimnoTech, Ann Arbor, Michigan; ${ }^{2}$ David J. Collins Engineering, Portland Oregon; ${ }^{3}$ City of Portland, Portland, Oregon.
}

\begin{abstract}
The City of Portland, Oregon recently completed construction of the Willamette combined sewer overflow tunnel system to contain combined sewage during storm events and prevent unauthorized release of sewage to the Willamette River. The system includes a network of consolidation conduits designed to intercept combined flows and convey them to tunnel drop shafts. After bringing the system online, the effects of pressure surges were observed at various locations along the conduits and interceptor sewers, including the displacement of manhole covers at two locations and, at one location where the manhole cover was bolted down, by pavement deformation. A subsequent modeling investigation focused on simulation of these target transient events to better understand the nature of the events and to provide a risk based understanding of them for mitigation design.

The target transient events in the consolidation conduits were modeled using a 1-dimensional finite volume model formulated specifically for rapidly varied, mixed flow systems. Inflows to the system were produced by a collection system model, using rainfall data collected during the modeled events. The downstream boundary of each model was defined by drop shaft water level data, collected during the events.

Preliminary modeling results did not show flooding to grade for the observed events, but did indicate pressurization of the air space underneath manhole covers. The model framework was modified to dynamically simulate pressurization of the air space in chambers above surcharged sewers, including venting of air via an orifice equation. Application of the enhanced model provided confidence that pressurization was the source of the observed events, and that additional venting would suffice to safely relieve pneumatic pressures. A subsequent design effort will focus on providing pneumatic relief to the systems.
\end{abstract}

\section{Introduction}

The City of Portland, Oregon recently completed construction of the Willamette combined sewer overflow (CSO) tunnel system to contain combined sewage during storm events and prevent unauthorized release of sewage to the Willamette River. The Willamette CSO tunnel system includes a network of consolidation conduits, which are designed to intercept combined flows upstream of CSO outfalls and convey the combined flows to drop shafts that discharge to deep CSO tunnels. As the CSO tunnel system was brought online, the challenges of consolidating and redirecting flows for the most extreme events became apparent, as the effect of pressure surges were observed at various locations along the conduits and interceptor sewers. The events were manifest by the displacement of manhole covers at two locations and, at one location where the manhole cover was bolted down, by pavement deformation. A subsequent modeling investigation focused on simulation of these target transient events to better understand the nature of the events and to provide a risk based understanding of them for mitigation design.

\section{Observed Events}

The Portland sewer system has experienced transient and pneumatic issues within particular consolidation conduits tributary to the East Side and West Side tunnels: the Oak-Stark-Alder OF37 and OF38 consolidation conduits, the Upshur-Tanner consolidation conduits, and the Alder trunk OF36 system. These three areas are shown on a general map of the tunnels in Figure 1. The Oak-Stark-Alder OF37 and OF38 consolidation conduit and the Alder trunk OF36 system both have the Alder shaft as their downstream confluence, which drains to the East Side tunnel. The Upshur-Tanner consolidation conduit has the Upshur shaft as its downstream confluence, which drains to the West Side tunnel. The level monitoring data for the Alder shaft and for the Upshur shaft both indicate that backwater extends into the consolidation conduits and trunk system from the CSO tunnels during certain

Klaver, Peter, David Collins, Kurt Robinson and Scott Bell. 2016. Modeling of Transient Pneumatic Events in a Combined Sewer Overflow Storage Tunnel System. Journal of Water Management Modeling 25:C409. https://doi.org/10.14796/JWMM.C409 @ CHI 2016. www.chijournal.org ISSN 2292-6062. 
wet weather events. The three events that showed some evidence of transient or pneumatic issues are described as follows:

- within the Oak-Stark-Alder OF37 and OF38 consolidation conduits, a manhole cover was found to be displaced from its frame on SE 3rd Avenue near SE Alder Street following a rain event on 2013-09-28; within the Upshur-Tanner consolidation conduits, a bolted manhole cover and manhole frame on NW 11th Avenue near NW Northrup Street was found to have heaved, and the surrounding asphalt pavement distorted, following a rain event on 2009-05-04; and within the Alder trunk OF36 system two manhole covers on SE 7th Avenue at SE Yamhill Street were observed being lifted and venting air during a rain event on 2012-05-26.

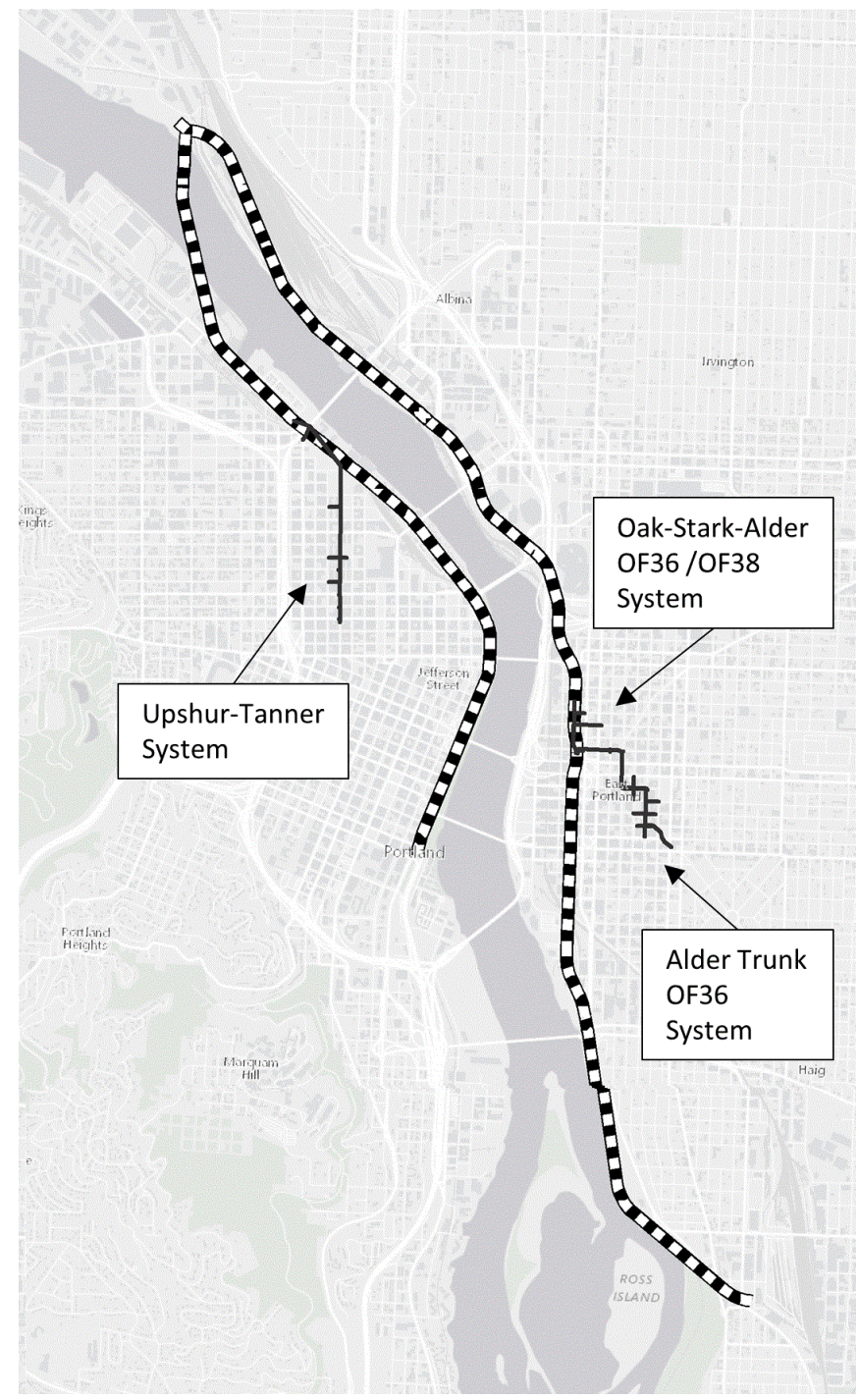

Figure 1 Area map showing location of observed transient issues for Portland East Side and West side CSO tunnels.
The City initiated a modeling study to better understand the causes of these events, so that appropriate steps could be taken to mitigate future occurrences. The study concluded that the observed events were pneumatic in nature, and that additional venting would suffice to safely relieve pneumatic pressures. $A$ subsequent design effort will focus on providing pneumatic relief to the systems.

\section{Modeling Approach}

The target transient events in the consolidation conduits were modeled using the SHAFT model framework, which is a 1-dimensional finite volume model formulated specifically for rapidly varied mixed flow systems. Inflows to the system were produced by a collection system model, using rainfall data collected during the modeled events. The downstream boundary condition of the SHAFT models was defined by drop shaft water level data, collected during the events.

The numerical basis of SHAFT has been fully documented elsewhere (Vasconcelos et al. 2006). The model is based on the 1-D Saint-Venant equations, written in conservative form and discretized over a finite volume framework. The state variables are defined at cell centers and the fluxes are defined at cell interfaces. The resulting Reimann problem is solved by Roe's method (Macchione and Morelli 2003). Transitions between free surface and pressurized flow are handled using the two component pressure approach (Vasconcelos et al. 2006). The modeling approach compared well against other transient flow solvers (Vasconcelos and Wright 2007). SHAFT has been applied to evaluate transient issues in the design of storage tunnels in Washington, DC and in London, England (Lautenbach et al. 2010).

For this modeling effort, the effects of air exhaust on pressures against manhole covers was of particular interest, and some additional capabilities were added to SHAFT to permit the evaluation of such effects. A fully dynamic simulation of the movement of air in the headspace of sewers flowing in open channel mode was beyond the scope of the present study; however, the pressure effect of water rising in a surcharged access structure was sufficiently constrained, and was implemented as a modification of the internal boundary condition used in SHAFT for such junctions.

Figure 2 shows schematically how a surcharged junction is modeled in SHAFT. Conservation of momentum at each conduit is represented by a lumped inertia approach, and continuity is enforced for the junction volume. The junction itself has no momentum, and the water depth represents a free surface condition. This leads to three ordinary differential equations as follows:

$$
\begin{aligned}
& \frac{d V_{L}}{d t}=\frac{g}{\Delta x}\left(y_{L}-H_{\text {junc }}-K_{\text {local }} \frac{\left|V_{L}\right| V_{L}}{2 g}\right) \\
& \frac{d V_{R}}{d t}=\frac{g}{\Delta x}\left(H_{\text {junc }}-y_{R}-K_{\text {local }} \frac{\left|V_{R}\right| V_{R}}{2 g}\right) \\
& \frac{d H_{\text {junc }}}{d t}=\frac{1}{A_{\text {junc }}}\left(V_{L} A_{L}-V_{R} A_{R}\right)
\end{aligned}
$$


where:

$V_{L}=$ velocity of flow on left side of junction $[\mathrm{L} / \mathrm{t}]$,

$V_{R}=$ velocity of flow on right side of junction $[\mathrm{L} / \mathrm{t}]$,

$y_{L}=$ hydraulic depth on left side of junction $[L]$,

$y_{R}=$ hydraulic depth on right side of junction [L],

$H_{\text {junc }}=$ depth in junction [L],

$K_{\text {local }}=$ local loss coefficient [--],

$A_{L}=$ flow area on left side of junction $\left[\mathrm{L}^{2}\right]$,

$A_{R}=$ flow area on right side of junction $\left[\mathrm{L}^{2}\right]$,

$A_{\text {junc }}=$ plan area of junction $\left[\mathrm{L}^{2}\right]$, and

$\Delta x=$ length of computational cell [L].

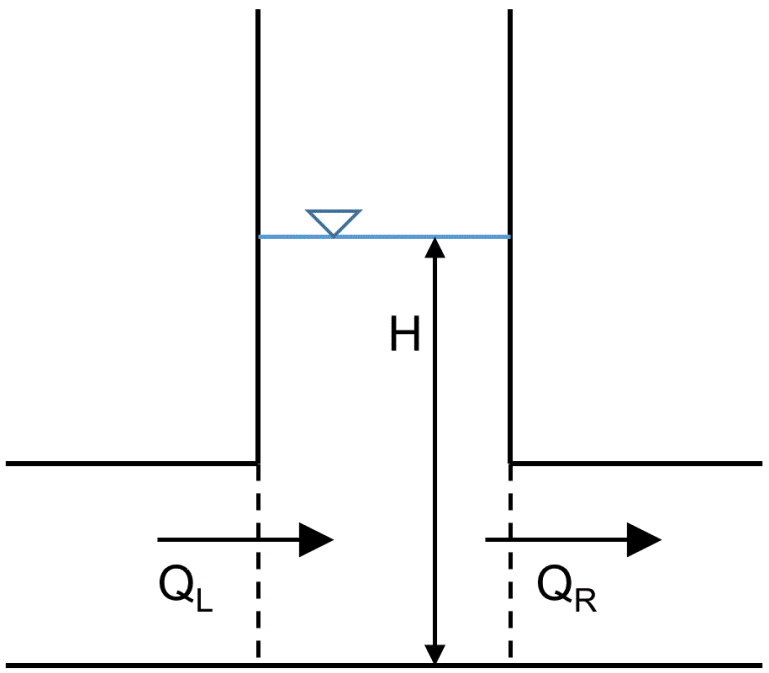

Figure 2 Schematic representation of surcharged junction.

Equations 1 and 2 represent linear momentum conservation at the left hand and right hand sides of the junction respectively, and Equation 3 represents continuity within the junction itself.

The modified internal boundary condition including air pressurization is shown in Figure 3 below. The general approach follows the work of Zhou et al. (2002). The pressure in the air space in the structure becomes an additional state variable in the model, and continuity of the air phase becomes an additional equation in the solution. The additional equation for the junction has the following form:

$$
\frac{d P}{d t}=-k \frac{P}{V_{\text {air }}}\left(Q_{\text {air }}+\frac{d V_{\text {air }}}{d t}\right)
$$

where:

$P=$ total pressure in the air space $\left[\mathrm{M} / \mathrm{Lt}^{2}\right]$,

$k=$ polytropic process coefficient [--],

$V_{\text {air }}=$ volume of air space $\left[\mathrm{L}^{3}\right]$, and

$Q_{\text {air }}=$ flow of air through opening to surface $\left[\mathrm{L}^{3} / \mathrm{t}\right]$.

For a sealed manhole the air flow is zero. For openings (pick holes, for example), the flow is represented by an orifice equation:

$$
Q_{a i r}=C_{d} A_{o} \sqrt{2 R T\left(1-\frac{P_{a t m}}{P}\right)}
$$

where:

$$
\begin{aligned}
C_{d} & =\text { orifice discharge coefficient }[--], \\
A_{o} & =\text { area of opening(s) }\left[\mathrm{L}^{2}\right], \\
R & =\text { gas constant for air }\left[\mathrm{L}^{2} / \mathrm{t}^{2} \mathrm{~T}\right], \\
T & =\text { absolute temperature }[\mathrm{T}], \text { and } \\
P_{a t m} & =\text { atmospheric pressure }\left[\mathrm{M} / \mathrm{Lt}^{2}\right] .
\end{aligned}
$$

Pressure is related to the volume of the air space by the ideal gas equation of state, with the volume change represented as a polytropic process. For an adiabatic process this coefficient would be the specific heat ratio, which is 1.4 for air. The change in volume of the air space is coupled to the change in water surface elevation by defining a ceiling elevation for the structure, as shown in Figure 3. The momentum equations are modified to include the air pressure term, added to the hydraulic head. The additional equations are solved by Runge-Kutta integration.

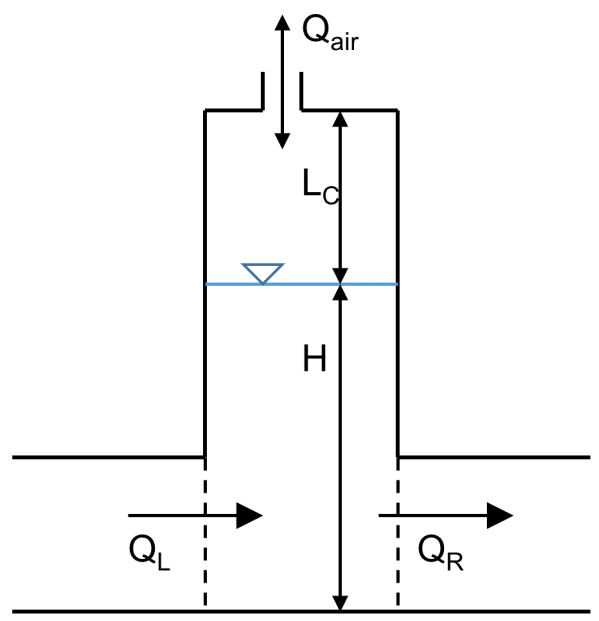

Figure 3 Schematic representation of surcharged junction including air pressurization.

It should be noted that the implementation described here does not handle the situation where the water surface elevation reaches the ceiling of the chamber. This was not an issue in the present study because flooding to grade did not occur in any of the simulations. However, in future cases the situation could be handled by allowing water to leave the structure through the orifice.

Boundary conditions for the SHAFT models consist of flow hydrographs, which are introduced at model junctions, and a water surface elevation time series that is imposed at the most downstream junction in each model. The flow hydrographs for the consolidation conduits and trunk line were provided by the City of Portland Bureau of Environmental Services (BES), derived from output from their collection system model. The water surface elevation boundary conditions were defined by time series of monitored water elevations in the Alder and Upshur drop shafts, which were also provided by BES staff. 


\section{Simulation Results}

This section discusses the results of the event modeling for each of the three SHAFT models.

\subsection{Alder Shaft System}

The 2013-09 event in the Alder shaft system was simulated beginning at 14:00 on September 28 and ending at 07:00 on September 29. Figure 4 shows a composite inflow hydrograph (that is, the sum of all three of the individual inflow hydrographs) along with the level in the Alder drop shaft. The inflows were produced with BES' collection system model, using observed rainfall from the event; the water surface levels are observed data from the event.

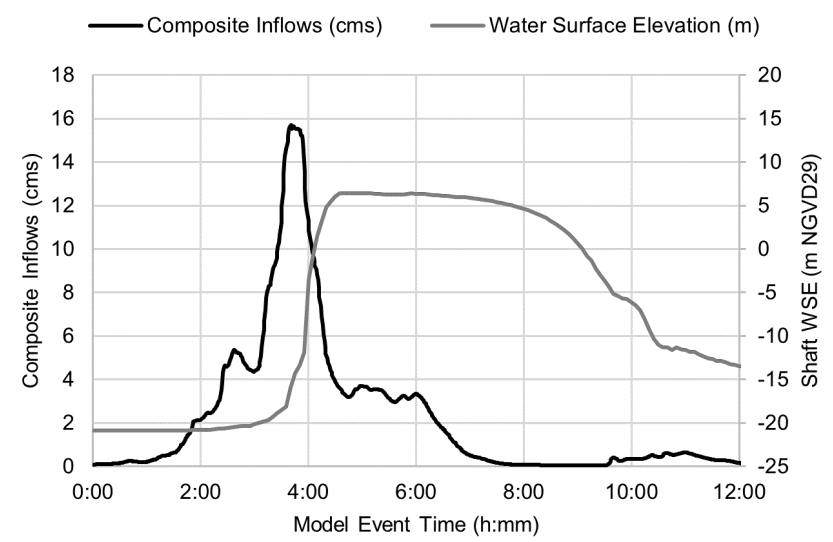

Figure 4 Modeled inflows and observed Alder shaft water surface elevation for the 2013-09 event.

Significant transient and pneumatic effects were calculated in the first $12 \mathrm{~h}$ of this period. Figure 5 presents hydraulic grade line (HGL) time series for the four manholes on the 84 in. $(2.13 \mathrm{~m})$ diameter consolidation conduit during the initial $12 \mathrm{~h}$ period. The four manholes proceed from the upstream end of the modeled domain (ANR533) to the downstream end (ANR278), where the water surface elevation is specified by data as shown in Figure 4.

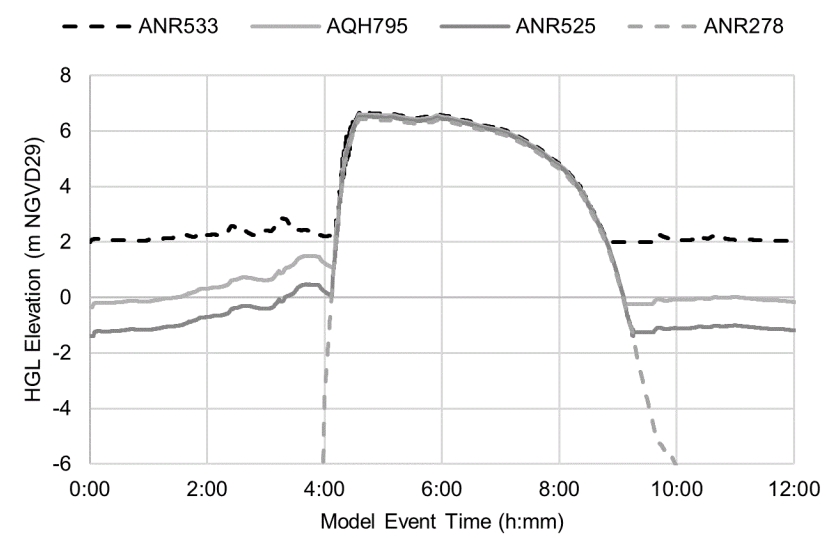

Figure 5 Modeled HGL time series at manholes along the 84 in. diameter Alder shaft system consolidation conduit for the 2013-09 event.
It is evident from the figures that HGLs in the $84 \mathrm{in} .(2.13 \mathrm{~m})$ diameter consolidation conduit are strongly influenced by the water surface elevation in the Alder shaft between hours 4:00 and 9:00 of the event. For sewer inverts above an elevation of about $20 \mathrm{ft}(6.1 \mathrm{~m})$, however, the Alder shaft water surface elevation has no visible impact. The highest flow rate from the Alder shaft system service area has already passed when the shaft elevation begins its steep rise (see Figure 4), so there does not appear to be a significant backwater effect for this particular event.

Pressure calculations were carried out in the surcharged portion of manhole ANR525, which was the location of the displaced cover. Air was presumed to escape through two 1 in. (25.4 $\mathrm{mm}$ ) diameter pick holes. Figure 6 shows the calculated pressure, as well as the equivalent force on the cover assuming a diameter of $24 \mathrm{in}$. $(0.61 \mathrm{~m})$. The calculated maximum force suggests that pneumatic effects resulting from the rise of water in the Alder shaft were sufficient to move the manhole cover, and possibly to dislodge it. Note that any lifting of the cover would allow additional air to escape the chamber, and thus lower the pressure more rapidly than is simulated by the model. Still, the model results indicate that pneumatic forces on the manhole cover were significant in this particular event.

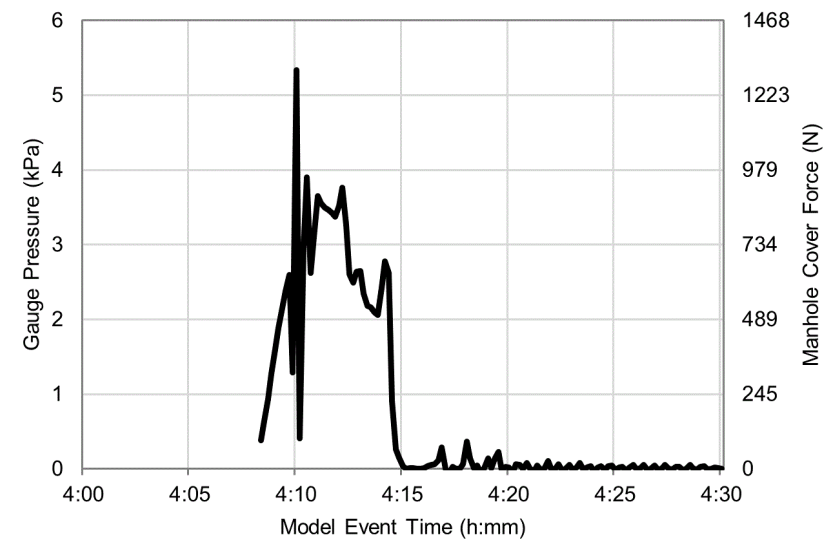

Figure 6 Pressure and force calculations at manhole ANR525 for the 2013-09 event.

\subsection{Upshur Shaft System}

The 2009-05-04 event on the Tanner Creek branch of the Upshur shaft system was simulated beginning at 12:40:00 and ending at 20:30:00, for a total simulation time of just $<8 \mathrm{~h}$. Figure 7 shows a composite inflow hydrograph along with the level in the Upshur drop shaft. As with the Alder shaft system, the inflows were produced with BES's collection system model, using observed rainfall from the event; the water surface levels are observed data from the event. In this event, the peak composite inflow to the Tanner Creek consolidation conduit occurs almost simultaneously with the steepest rate of rise in the Upshur shaft at the downstream boundary. This happens some $5 \mathrm{~h}$ into the event, and so the model results presented here focus on this later period of the simulation. 


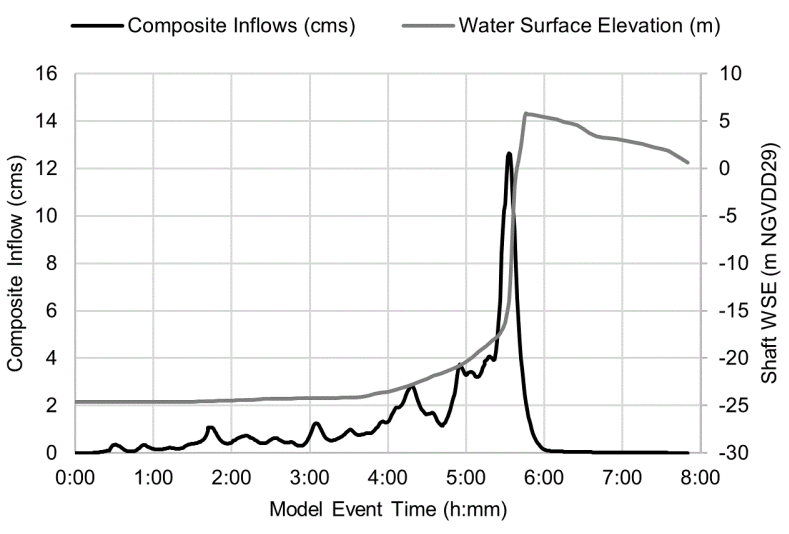

Figure 7 Modeled inflows and observed Upshur shaft water surface elevation for the 2009-05-04 event.

Time series HGLs for manholes on the 72 in. (1.83 m) consolidation conduit are shown in Figure 8. This event contrasts sharply with the 2013-09 event in the Alder shaft system, in which flows were relatively low and the HGL was dominated by the shaft level. Here there are oscillations in response to pressurization transients, and an overall lag in response time between the rise at the shaft and higher HGLs at upstream locations.

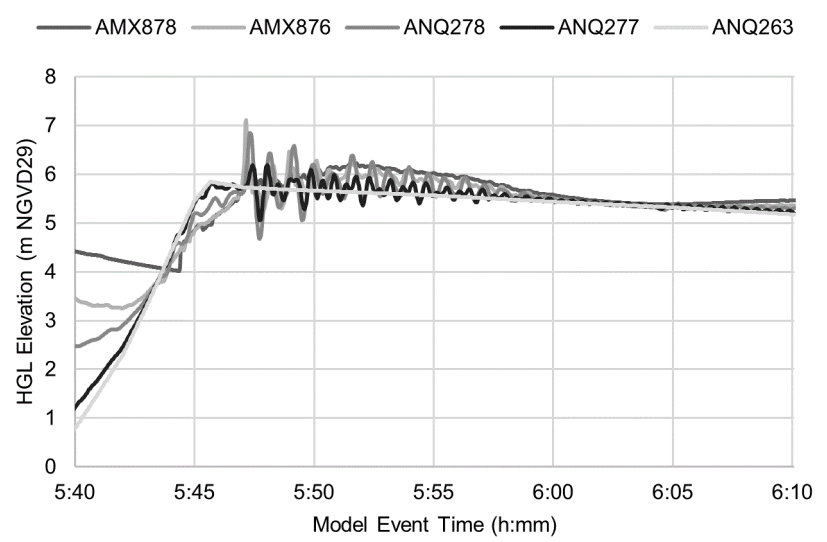

Figure 8 Modeled HGL time series at manholes on $72 \mathrm{in}$. Tanner Creek consolidation conduit (Upshur shaft system) for the 2009-05-04 event.

Pressurization and force calculations for the chamber at AMX876 are of interest, as this was the location where structural damage was observed. As the manhole cover is bolted and sealed, the orifice area was set to zero in the model. Figure 9 presents the modeled pressure in the chamber, along with the resultant force on a $28 \mathrm{in}$. $(0.36 \mathrm{~m})$ diameter manhole cover. The maximum force of $\sim 500 \mathrm{lb}(6700 \mathrm{~N})$ is considerable, and believed to be capable of distorting the manhole cover frame. The corresponding peak force on the $10 \mathrm{ft}(3.0 \mathrm{~m})$ diameter concrete lid of the chamber is about $25000 \mathrm{lb}(111000 \mathrm{~N})$. This is roughly estimated to be of the same order as the weight of the top slab of the chamber with the overlying asphalt pavement.

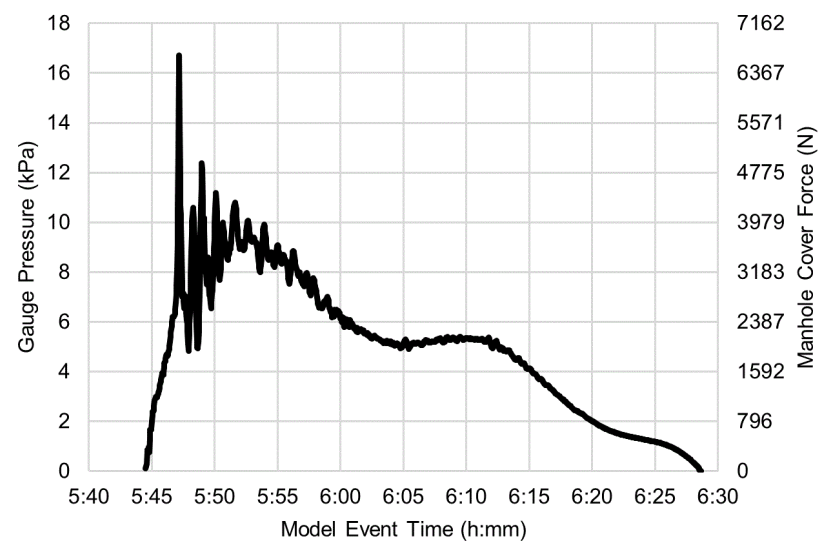

Figure 9 Pressure and force calculations at manhole AMX876 for the 2009-05-04 event.

\subsection{Alder Trunk System}

The 2012-05-26 event on the Alder trunk system was simulated beginning at 18:50 and ending $4 \mathrm{~h}$ later at 22:50. Unlike the events modeled for the Alder shaft system and the Upshur shaft system, the monitored water surface elevation in the downstream tunnel drop shaft did not rise high enough to influence flows in the surface sewers. However, both open channel and pressurized bores were observed at various places in the system in response to the rapid filling of the event. These in turn have an influence on air movement in the sewers, which provides some insight into the observed surface venting at the manholes at Yamhill and 7th Ave.

Figure 10 presents HGL time series at manholes AMY001 and AMY004, which are the two manholes where lifting and venting were observed during the rain event. The two manholes become briefly surcharged, although the period of time they are surcharged may not fully account for the observed movements of the covers.

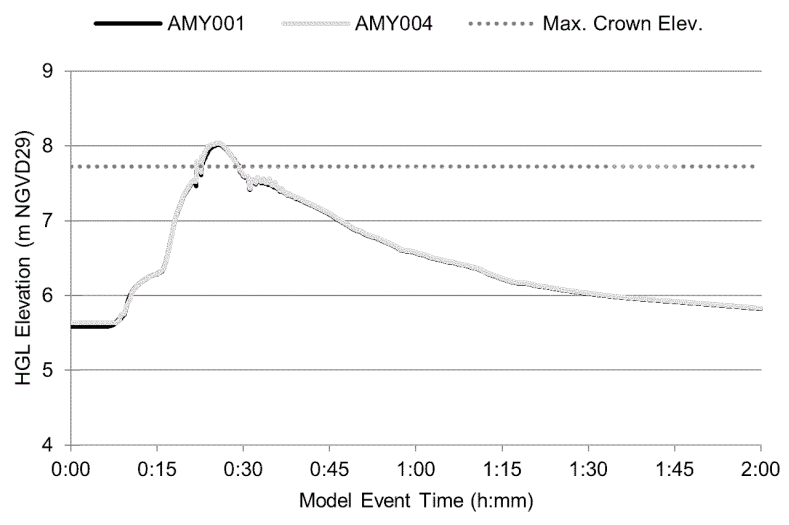

Figure 10 Modeled HGL time series at manholes AMY001 and AMY004 for the 2012-05-26 event.

Figure 11 presents modeled pressures and force calculations at manhole AMY001; the results for AMY004 were similar 
and are not shown. At AMY001, the maximum calculated force was $610 \mathrm{lb}(2700 \mathrm{~N})$; at AMY004, the maximum calculated force was $480 \mathrm{lb}(2100 \mathrm{~N})$. It should be noted that the model was run using a range of roughness values for the sliplined pipe, which is expected to be smoother than conventional concrete pipes. A Manning's $n$ value of 0.011 was selected for the results shown here, based on calibrated values from the BES collection system model. Instances of negative pressure represent times when the water surface elevation in the manholes is dropping.

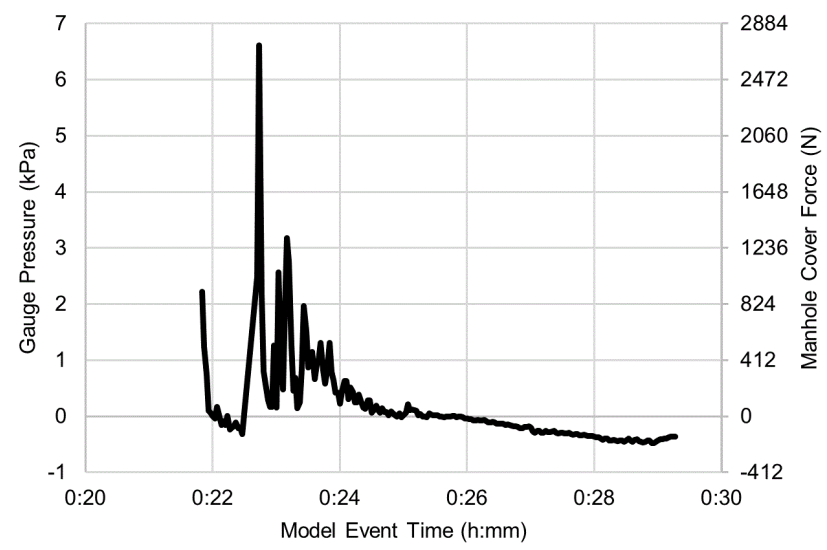

Figure 11 Pressure and force calculations at manhole AMY001 for the 2012-05-26 event.

Pneumatic issues at manholes AMY001 and AMY004 may not be limited to surcharged conditions, however, so an additional approach was conducted to assess air release. The flow of air in gravity sewers resulting from drag force transferred from flowing water is well understood (Edwini-Bonsu et al. 2006), although it is typically modeled as a steady state process rather than a dynamic process. In a general sense, air may be expected to exhaust preferentially at locations where the carrying capacity via drag is suddenly reduced, for example an increase in water depth that decreases the cross sectional area of the headspace in the sewer. This is notably the case at the location in question here: the two parallel branches of $66 \mathrm{in.}(1.68 \mathrm{~m})$ and $84 \mathrm{in}$. (2.13 m) diameter sewers join to form a single $69 \mathrm{in}$. (1.75 $\mathrm{m}$ ) diameter sewer, which even at a low roughness characteristic of FRP pipe results in a sharp decrease in headspace at higher flows. An estimate of the air flow capacity in the parallel sewer branches as well as the single 69 in. (1.75 m) diameter branch downstream of AMY001 is shown in Figure 12, using methods described in Edwini-Bonsu and Steffler (2006). The calculations were made from the SHAFT model run that used pipe roughness of 0.009 , as this was the run in which the manholes of interest did not become surcharged. The 66 in. (1.68 m) and 84 in. $(2.13 \mathrm{~m})$ branches together have the potential to deliver nearly twice the airflow that can be carried through the $69 \mathrm{in}$. (1.75 m) branch downstream. The differences in these capacities (that is, the incoming flows minus the outgoing flows) may be taken as a quantity of air that may be required to be exhausted at manhole AMY001; this quantity is shown in Figure 13, along with a potential exhaust rate at AMY004 calculated in a similar way. The calculations are approximate, based on the assumption that the air phase velocity responds nearly instantaneously to changes in the water surface velocity. The result is useful, nonetheless, as an estimate of the degree of ventilation that may be required to mitigate pressurization effects at this location.

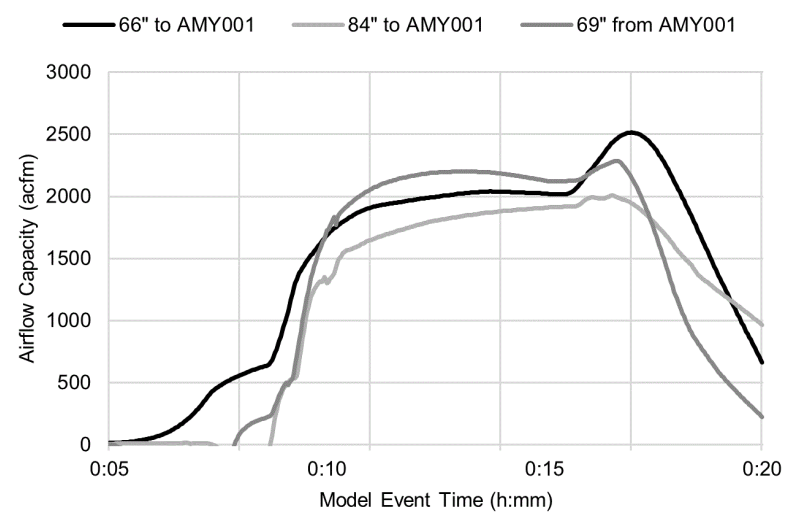

Figure 12 Estimated airflow capacities in Alder trunk sewer for the 2012-05-26 event.

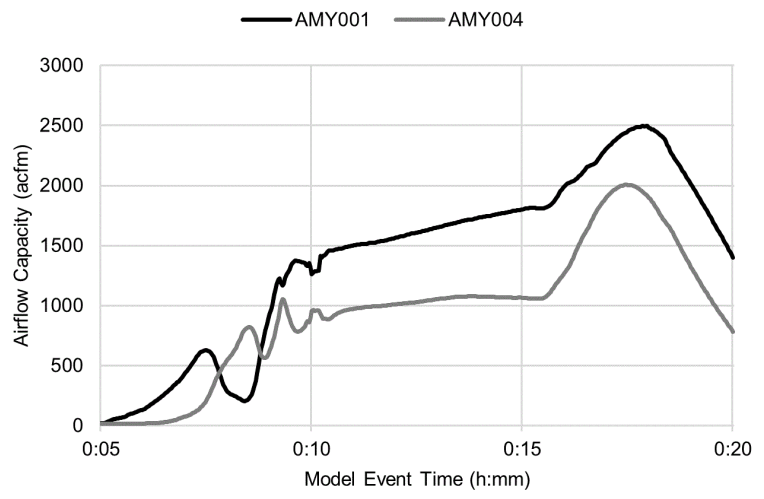

Figure 13 Differential airflow capacities (incoming flows minus outgoing flows) at manholes AMY001 and AMY004 for the 2012-05-26 event.

\section{Conclusions}

Models were developed, using the SHAFT framework, of the Alder shaft system, the Upshur shaft system, and the Alder trunk system. Each of these models was then run using boundary conditions, supplied by BES, that represented actual system events during certain transient or pneumatic phenomena were either observed, or believed to occur. The modeling results may be reasonably interpreted to explain the observed events in terms of the imposed boundary conditions; that is, inflows to the consolidation conduits and water levels in the drop shafts. Conclusions specific to each modeled system are presented below. 
1. In the Alder shaft system, a rapid rise in water level in the Alder drop shaft resulted in increases in level in the consolidation conduit. While backflow into the conduit was not large in this instance, the level rise was rapid enough to cause pressurization within the manhole where the cover was displaced (ANR525). The modeled pressurization appeared to be great enough to lift the manhole cover, at least momentarily, and possibly enough to completely dislodge it.

2. In the Upshur shaft system, a rapid rise in water level in the Upshur drop shaft resulted in a pressurized bore traveling up the conduit. The pressurized bore occurred because the conduit was still carrying a considerable amount of flow at the time of the level rise in the drop shaft. The progress of the bore upstream resulted in pressurization in the manhole chamber where the structural damage was observed. Modeled pressures in this chamber appear to be capable of causing the observed damage.

3. In the Alder trunk system, the potential for pneumatic issues was identified based on the dynamics of flow in the conduits themselves, unrelated to the water level in the Alder shaft. The location where manhole cover lifting was observed (manholes AMY001 and AMY004) is just upstream of where a $66 \mathrm{in.}(1.67 \mathrm{~m}$ ) diameter pipe and an $84 \mathrm{in}$. ( $2.13 \mathrm{~m}$ ) diameter pipe join to a single $69 \mathrm{in}$. (1.75 m) diameter pipe. The resulting reduction in hydraulic conveyance capacity provides a potential for excessive pneumatic pressure at these manholes either through (a) surcharging of the 69 in. pipe, or (b) a sharp reduction in the air flow capacity of the sewer because of the reduction in open space above the water surface.

In summary, the SHAFT models documented here simulate conditions that explain the phenomena observed at each of the three subject locations reasonably well. In addition, the model results indicate that the phenomena occurred because of hydraulically-driven, pneumatic pressure forces on at-grade manhole structures, as opposed to direct hydraulic forces, which is an important finding for the identification of potential mitigation measures. The results can be used to inform the design of ventilation structures to prevent future reoccurrences of such phenomena.

\section{References}

Edwini-Bonsu, S. and P. M. Steffler. 2006. “Modeling Ventilation Phenomenon in Sanitary Sewer Systems: A System Theoretic Approach." Journal of Hydraulic Engineering 132 (8): 778-90.

Lautenbach, D. H., J. K. Marr, P. R. Klaver, J. F. Cassidy and D. Crawford. 2010. "A Tale of Two Capitals: Modeling Helps Designers Manage Strong Surge and Pneumatic Forces in Deep Combined Sewer Storage Tunnels." In North American Tunneling: 2010 Proceedings, 483-50. Littleton, CO: Society for Mining, Metallurgy \& Exploration.

Macchione, F. and M. A. Morelli. 2003. "Practical Aspects in Comparing the Shock-Capturing Schemes for Dam Break Problems." Journal of Hydraulic Engineering 129 (3): 187-95.

Vasconcelos, José and Steven Wright. 2007. “Comparison Between the Two-Component Pressure Approach and Current Transient Flow Solvers." Journal of Hydraulic Research 45 (2): 178-87.

Vasconcelos, José, Steven Wright and Philip Roe. 2006. "Improved Simulation of Flow Regime Transition in Sewers: Two-Component Pressure Approach." Journal of Hydraulic Engineering 132 (6): 553-62.

Zhou, F., F. E. Hicks and P. M. Steffler. 2002 "Transient Flow in a Rapidly Filling Horizontal Pipe Containing Trapped Air." Journal of Hydraulic Engineering 128 (6): 625-34. 